\title{
The associated pyrazolopyrimidines PP1 and PP2 inhibit protein tyrosine kinase 6 activity and suppress breast cancer cell proliferation
}

\author{
HYUN JAE SHIM ${ }^{1}$, HAN IE KIM ${ }^{1,2}$ and SEUNG-TAEK LEE ${ }^{1}$ \\ ${ }^{1}$ Department of Biochemistry, College of Life Science and Biotechnology, Yonsei University, Seoul 03722, Republic of Korea
}

Received August 12, 2015; Accepted November 17, 2016

DOI: $10.3892 / \mathrm{ol} .2017 .5564$

\begin{abstract}
Protein tyrosine kinase (PTK)6, also known as breast tumor kinase, is a non-receptor tyrosine kinase. It is closely associated with, but evolutionarily distinct from, the Src family members. PTK6 has a role in proliferation, migration and invasion in various cancers, and therefore has been suggested as a potentially valuable therapeutic target. In an attempt to develop PTK6 inhibitors, chemicals known to inhibit various kinases were screened for their ability to inhibit PTK6. Pyrazolopyrimidine (PP)1, PP2 and a lymphocyte-specific protein tyrosine kinase inhibitor strongly inhibited the catalytic activity of PTK6 in vitro. These chemicals suppressed the phosphorylation of PTK6 substrate proteins, including signal transducer and activator of transcription 3, in human embryonic kidney (HEK) 293 cells expressing hyperactive PTK6. They also expressed selectivity towards PTK6 over other PTK members in HEK 293 cells. PP1 and PP2 specifically inhibited the PTK6-dependent proliferation of human breast carcinoma T-47D cells. PP1 and PP2 were more selective for PTK6 than for Src family kinases, and may be useful for the treatment of PTK6-positive malignant diseases such as breast cancer.
\end{abstract}

\section{Introduction}

Protein tyrosine kinase (PTK)6, also known as breast tumor kinase, is a non-receptor type kinase that consists of an Src homology (SH)3 domain, an $\mathrm{SH} 2$ domain and a catalytic domain of tyrosine kinase $(1,2)$. PTK6 is overexpressed in $>60 \%$ of breast carcinoma tissue samples and in the majority of

Correspondence to: Professor Seung-Taek Lee, Department of Biochemistry, College of Life Science and Biotechnology, Yonsei University, 50 Yonsei-Ro, Seodaemun-Gu, Seoul 03722, Republic of Korea

E-mail: stlee@yonsei.ac.kr

Present address: ${ }^{2}$ Department of Life Science and Biotechnology, Shingyeong University, Hwaseong, Gyeonggi-do 18274, Republic of Korea

Key words: PP1, PP2, PTK6 inhibitor, breast cancer cell breast cancer cell lines (3). PTK6 expression is also increased in colon, head and neck, ovary, prostate, lung, bladder, bile duct, pancreas and gastric cancers, and in T- and B-cell lymphomas $(4,5)$.

Expression of PTK6 enhances the proliferation of mammary epithelial and breast cancer cells (6). PTK6 also promotes cell migration and invasion (7). Sublocalization of PTK6 at the plasma membrane is important for its oncogenic potential (8). Activated PTK6 consistently accumulates at the plasma membrane in breast cancer cell lines and tissues (9). Although PTK6 was detected in the nucleus and cytoplasm of normal mammary gland epithelial cells, Tyr342 in the PTK6 activation loop was not phosphorylated, and thus, PTK6 was not active (9).

PTK6 promotes tumorigenicity by enhancing signaling pathways of receptor tyrosine kinases and is particularly well known for sensitizing epidermal growth factor receptor (EGFR) family members (10). Various downstream substrates and interacting proteins, including signal transducing adaptor protein-2, paxillin, Akt, p130 Crk-associated substrate, p190Rho GTPase-activating protein-A and ArfGAP with RhoGAP domain, ankyrin repeat and PH domain 1, contribute to the oncogenic roles of PTK6 $(11,12)$. Similar to other PTKs, mutations of PTK6 identified in different cancer types increase its kinase activity (13).

In view of its oncogenic activity and its presence in various carcinomas such as breast cancer, PTK6 is a potentially valuable therapeutic target for decelerating or arresting tumor growth (14). (E)-5-(Benzylideneamino)-1H-benzo[d] imidazol-2(3H)-one derivatives were previously developed as novel PTK6 inhibitors that exhibited little cytotoxicity, excellent inhibition in vitro and at the cellular level, and selectivity for PTK6 (15). Imidazo[1,2-a]pyrazin-8-amines and 4-anilino $\alpha$-carbolines were also identified as PTK6-selective inhibitors that block its catalytic activity $(16,17)$. In the present study, pyrazolopyrimidine (PP)1 [4-amino-5(4-methylphenyl)-7-(t-butyl) pyrazolo[3,4-d]pyrimidine], PP2 [(4-amino-5-(4-chlorophenyl)-7-(t-butyl) pyrazolo[3,4-d] pyrimidine] and a lymphocyte-specific protein tyrosine kinase (Lck) inhibitor [4-amino-5-(4-phenoxyphenyl)-7H-pyrrolo [3,2-d]pyrimidin-7-yl-cyclopentane] were screened as potent PTK6 inhibitors among the evaluated kinase inhibitors. The selectivity of these compounds for PTK6 and for other PTK family members was analyzed in HEK 293 cells, and 
it was then examined whether these compounds inhibited PTK6-dependent signaling processes and the proliferation of breast carcinoma T-47D cells.

\section{Materials and methods}

Chemicals. PP1, PP2 and the aforementioned Lck inhibitor were purchased from Calbiochem (EMD Millipore, Billerica, MA, USA). Genistein was purchased from Santa Cruz Biotechnology, Inc. (Dallas, TX, USA).

Cell culture. Human embryonic kidney (HEK) 293 cells and human breast cancer T-47D cells (both American Type Culture Collection, Manassas, VA, USA) were maintained in Dulbecco's modified Eagle's medium (DMEM; Gibco; Thermo Fisher Scientific, Inc., Waltham, MA, USA) containing 10\% fetal bovine serum (FBS; HyClone; GE Healthcare Life Sciences, Logan, UT, USA) at $37^{\circ} \mathrm{C}$ in a $\mathrm{CO}_{2}$ incubator with a humidified atmosphere of $5 \% \mathrm{CO}_{2}$ and $95 \%$ air.

ELISA-based in vitro kinase assay for PTK6. ELISA plates (96-well; Greiner Bio-One GmbH, Frickenhausen, Germany) were incubated with $100 \mu \mathrm{l}$ of $0.1 \mathrm{mg} / \mathrm{ml}$ Poly (Glu, Tyr) (Glu:Tyr, 4:1; Sigma-Aldrich; Merck Millipore, Darmstadt, Germany) in PBS for $16 \mathrm{~h}$ at $37^{\circ} \mathrm{C}$, and then washed three times with PBS. The Poly (Glu, Tyr)-coated wells were blocked with $1 \%$ bovine serum albumin in PBS for $1 \mathrm{~h}$ at $37^{\circ} \mathrm{C}$, washed three times with PBS, and then incubated for $30 \mathrm{~min}$ at room temperature with $10 \mathrm{nM}$ glutathione $\mathrm{S}$-transferase-fused PTK6 catalytic domain (18) in $20 \mu$ of kinase reaction buffer [20 mM Tris- $\mathrm{HCl}$ (pH 7.4), $10 \mathrm{mM} \mathrm{MgCl} 2,1 \mathrm{mM} \mathrm{MnCl}_{2}$ and $\left.50 \mu \mathrm{M} \mathrm{Na} \mathrm{NO}_{4}\right)$ in the presence of the chemical of interest (Table I) containing a final concentration of $1 \%$ dimethyl sulfoxide. The phosphorylation of tyrosine residues was initiated by addition of $300 \mu \mathrm{M}$ adenosine triphosphate (ATP) to the reaction mixtures. The wells were washed three times with PBS after incubation for $20 \mathrm{~min}$ at room temperature. For the quantification of phosphorylated tyrosines, the wells were incubated with anti-phospho-tyrosine (4G10; 1:1,000; EMD Millipore) and horseradish peroxidase-conjugated anti-mouse immunoglobulin G (K0211589; 1:10,000; Koma Biotech, Seoul, Korea) antibodies for $1 \mathrm{~h}$ each at room temperature. The optical density was measured with a 3,3',5,5'-tetramethylbenzidine solution (Thermo Fisher Scientific, Inc.) according to the manufacturer's protocol.

Western blot analysis. HEK 293 cells expressing hyperactive PTK6 (Flag-PTK6-3PA/Y447F) (19), Src, Fyn, Lck, bone marrow tyrosine kinase gene on chromosome $\mathrm{X}(\mathrm{Bmx})$ or EGFR were treated with the indicated concentrations of compounds for 2 days. Western blot analysis and immunoprecipitation were performed as previously described (15). Immunoreactive proteins were visualized using anti-phospho-tyrosine (4G10; 1:1,000), anti-PTK6 (sc-1188; 1:2,000; Santa Cruz Biotechnology, Inc.), anti-phospho-signal transducer and activator of transcription (STAT)3 (sc-8059; 1:2,000; Santa Cruz Biotechnology, Inc.), anti-STAT3 (sc-7179; 1:2,000; Santa Cruz Biotechnology, Inc.) and anti-GAPDH (AbC-2003, 1:2,000; AbClon, Inc., Seoul, Korea) primary antibodies overnight at $4^{\circ} \mathrm{C}$, followed by incubation with a horseradish peroxidase-conjugated secondary antibody (K0211589 or K0211708; 1:10,000; Koma Biotech, Seoul, Republic of Korea) for $1 \mathrm{~h}$ at room temperature and an enhanced chemiluminescence detection kit (EMD Millipore). For the quantification of the phosphorylation levels in the cell lysates, chemiluminescence was detected using a LAS-3000 imaging system (Fujifilm, Tokyo, Japan) and analyzed using Multi Gauge version 2.2 software (Fujifilm). The half maximal inhibitory concentration $\left(\mathrm{IC}_{50}\right)$ at the cellular level was determined by quantifying the phosphorylation levels in the HEK 293 cell system. The reference level was the phosphorylation level of the chemical-free control, which was set at $100 \%$.

MTT assay. Subconfluent empty vector-transfected and PTK6-knockdown T-47D cells were incubated for 4 days in DMEM-10\% FBS containing various concentrations of the chemicals. Viable cells were measured using MTT assay, as previously described (15). The viability of chemical-free, vector-transfected T-47D cells was set at $100 \%$.

Statistical analysis. All data were expressed as the mean \pm standard deviation of three independent experiments. Statistical analysis was performed using Microsoft Excel (version, 2007; Microsoft Corporation, Redmond, WA, USA). The significant differences between the groups were assessed using a Student's t-test. $\mathrm{P}>0.05$ was considered to indicate a statistically significant difference.

\section{Results}

$P P 1, P P 2$ and Lck inhibitor inhibit the catalytic activity of PTK6 in vitro. Protein kinase inhibitors were analyzed for the inhibition of the PTK6 catalytic activity using an ELISA-based in vitro kinase assay system for PTK6. Among the tested kinase inhibitors, PP1, PP2 and the Lck inhibitor exhibited strong inhibition of PTK6 (Table I). The $\mathrm{IC}_{50}$ values for PP1, PP2 and the Lck inhibitor were 230.0, 50.0 and $60.0 \mathrm{nM}$, respectively (Table II).

PP1, PP2 and Lck inhibitor are highly selective for PTK6 at the cellular level. PP1, PP2 and the aforementioned Lck inhibitor were developed as Src family kinase (SFK) inhibitors $(20,21)$. The present study analyzed the selectivity of each inhibitor for the inhibition of several PTKs, including PTK6, SFK members (Src, Fyn and Lck), a non-receptor type PTK (Bmx) and a receptor type PTK (EGFR). HEK 293 cells expressing hyperactive PTK6, Src, Fyn, Lck, Bmx or EGFR were incubated in the presence of various concentrations of these inhibitors. Inhibition of each PTK activity at the cellular level was assessed for each inhibitor by measuring the decrease in tyrosine phosphorylation levels of cellular proteins via western blot analysis using an anti-phospho-tyrosine antibody. As expected, PP1, PP2 and the Lck inhibitor exhibited strong inhibition of SFK members. The $\mathrm{IC}_{50}$ value of PP1 to Lck was $1.76 \mu \mathrm{M}$; the $\mathrm{IC}_{50}$ value of PP2 to Lck was $4.36 \mu \mathrm{M}$; and the $\mathrm{IC}_{50}$ values of the Lck inhibitor to Lck, Fyn and Src were $0.37,1.22$ and $3.46 \mu \mathrm{M}$, respectively (Table III). Unexpectedly, PP1, PP2 and the Lck inhibitor inhibited PTK6 to a greater degree than SFK members. The $\mathrm{IC}_{50}$ values of PP1, PP2 and the Lck inhibitor to PTK6 were 2.5, 13.0 and $53.0 \mathrm{nM}$, respectively (Table III and Fig. 1, top panel). 
Table I. PTK6 inhibitory activities of protein kinase inhibitors screened from a targeted kinase inhibitor.

\begin{tabular}{|c|c|c|c|c|}
\hline Chemical name & $\begin{array}{l}\text { PubChem compound } \\
\text { identifier }\end{array}$ & $\begin{array}{c}\text { Molecular } \\
\text { weight (Da) }\end{array}$ & Known target & $\begin{array}{l}\text { In vitro } \\
\mathrm{IC}_{50}(\mathrm{nM})^{\mathrm{a}}\end{array}$ \\
\hline Genistein & 5280961 & 270.2 & PTKs & $>10,000$ \\
\hline PP1 & 1400 & 281.4 & Src, Fyn & $<300$ \\
\hline PP2 & 4878 & 301.8 & Lck, Fyn, Hck & $<300$ \\
\hline Lck inhibitor & 6603792 & 370.5 & Lck, Src & $<300$ \\
\hline LFM-A13 & 54676905 & 360.0 & Btk & $>10,000$ \\
\hline JAK inhibitor I & 5494425 & 309.3 & JAK $1-3$ & $>10,000$ \\
\hline Syk inhibitor & 6419747 & 353.4 & Syk & $>3,000$ \\
\hline Emodin & 3220 & 270.2 & Lck, ErbB2 & $>10,000$ \\
\hline Erbstatin analog & 5353609 & 194.2 & EGFR, Abl & $>300$ \\
\hline Lavendustin C & 3896 & 275.3 & EGFR, Src, CaMKII & $>300$ \\
\hline Daphnetin & 5280569 & 178.1 & EGFR, PKA, PKC & $>3,000$ \\
\hline PD 157432 & 10085225 & 283.3 & EGFR, ErbB2 & $>10,000$ \\
\hline Flt-3 inhibitor & 1048845 & 360.4 & Flt-3 & $>10,000$ \\
\hline cFMS inhibitor & 11617559 & 366.4 & FMS & $>10,000$ \\
\hline GTP-14564 & 3385203 & 234.3 & FMS, Kit, Flt-3, PDGFRB & $>10,000$ \\
\hline PDGFR inhibitor I & 5330535 & 276.3 & PDGFRB & $>10,000$ \\
\hline Oxindole I & 5908088 & 210.2 & VEGFR1, PDGFRB & $>10,000$ \\
\hline VEGFR2 inhibitor II & 23301538 & 343.2 & VEGFR2, PDGFRB & $>3,000$ \\
\hline TrkA inhibitor & 5413390 & 315.4 & TrkA & $>10,000$ \\
\hline Picropodophyllin & 72435 & 414.4 & IGF1R & $>10,000$ \\
\hline JNK inhibitor II & 8515 & 220.2 & JNK1-3 & $>10,000$ \\
\hline
\end{tabular}

${ }^{\mathrm{a}} \mathrm{The} \mathrm{IC}_{50}$ value was the concentration of each inhibitor required for $50 \%$ inhibition of the catalytic activity of purified PTK6 in the absence of inhibitors (dimethyl sulfoxide). Data were obtained from three independent experiments, each performed in duplicate. $\mathrm{IC}_{50}$, half maximal inhibitory concentration; PTK, protein tyrosine kinase; PP, pyrazolopyrimidine; Lck, lymphocyte-specific protein tyrosine kinase; LFM-A13, leflunomide metabolite-analog A13; STAT, signal transducer and activator of transcription; JAK, Janus-associated kinase; Syk, spleen tyrosine kinase; PD, Parke-Davis; Flt, Fms-like tyrosine kinase; cFMS, cellular feline McDonough sarcoma; GTP, guanosine triphosphate; PDGFRB, platelet-derived growth factor receptor beta; VEGFR, vascular endothelial growth factor receptor; TrkA, tropomyosin receptor kinase A; JNK, c-Jun N-terminal kinase; Hck, hematopoietic cell kinase; Btk, Bruton's tyrosine kinase; EGFR, epidermal growth factor receptor; Abl, Abelson murine leukemia viral oncogene homolog 1; CaMKII, $\mathrm{Ca}^{2+} /$ calmodulin-dependent protein kinase II; PK, protein kinase; IGF1R, insulin-like growth factor 1 receptor.

Table II. Inhibition of the catalytic activity of purified PTK6 by selected kinase inhibitors in vitro.

\begin{tabular}{|c|c|c|c|}
\hline Chemical name & Structure & $\begin{array}{c}\text { Molecular } \\
\text { weight (Da) }\end{array}$ & $\begin{array}{c}\text { In vitro } \\
\mathrm{IC}_{50}(\mathrm{nM})^{\mathrm{a}}\end{array}$ \\
\hline PP1 & & 301.8 & $230 \pm 20$ \\
\hline PP2 & & 317.4 & $50 \pm 10$ \\
\hline Lck inhibitor & & 370.5 & $60 \pm 20$ \\
\hline
\end{tabular}

${ }^{\mathrm{a}} \mathrm{The} \mathrm{IC}_{50}$ value was the concentration of each inhibitor required for $50 \%$ inhibition of the catalytic activity of purified PTK6 in the absence of inhibitors (dimethyl sulfoxide). Data are expressed as the mean \pm standard deviation values of three independent experiments, each performed in duplicate. $\mathrm{IC}_{50}$, half maximal inhibitory concentration; PTK, protein tyrosine kinase; PP, pyrazolopyrimidine; Lck, lymphocyte-specific protein tyrosine kinase. 
Table III. Selectivity of genistein, PP1, PP2 and a Lck inhibitor for various PTKs in the HEK 293 cell system.

\begin{tabular}{lcccc}
\hline & & \multicolumn{2}{c}{$\mathrm{IC}_{50}$ at the cellular level (nM) } & \\
\cline { 2 - 5 } PTKs & Genistein & PP1 & PP2 & Lck inhibitor \\
\hline PTK6 & $43,180 \pm 1,340$ & $2.5 \pm 0.3$ & $13 \pm 2$ & $53 \pm 7$ \\
Src & $>100,000$ & $70,300 \pm 7,320$ & $53,060 \pm 8,230$ & $3,460 \pm 850$ \\
Fyn & $70,640 \pm 8,520$ & $13,630 \pm 3,160$ & $35,980 \pm 1,030$ & $1,220 \pm 50$ \\
Lck & $>100,000$ & $1,760 \pm 250$ & $4,360 \pm 730$ & $370 \pm 40$ \\
Bmx & $69,550 \pm 7,460$ & $2,390 \pm 430$ & $16,460 \pm 2,780$ & $15,980 \pm 3,680$ \\
EGFR & $24,830 \pm 1,590$ & $21,840 \pm 1,140$ & $56,800 \pm 3,920$ & $>10,000$ \\
\hline
\end{tabular}

${ }^{a}$ The $\mathrm{IC}_{50}$ values were determined by quantifying the phosphorylation levels in HEK 293 cells expressing hyperactive PTK6, Src, Fyn, Lck, Bmx or EGFR. Data are expressed as the mean \pm standard deviation values of three independent experiments. HEK, human embryonic kidney; $\mathrm{IC}_{50}$, half maximal inhibitory concentration; PTK, protein tyrosine kinase; PP, pyrazolopyrimidine; Lck, lymphocyte-specific protein tyrosine kinase; EGFR, epidermal growth factor receptor; Bmx, bone marrow tyrosine kinase gene on chromosome X.

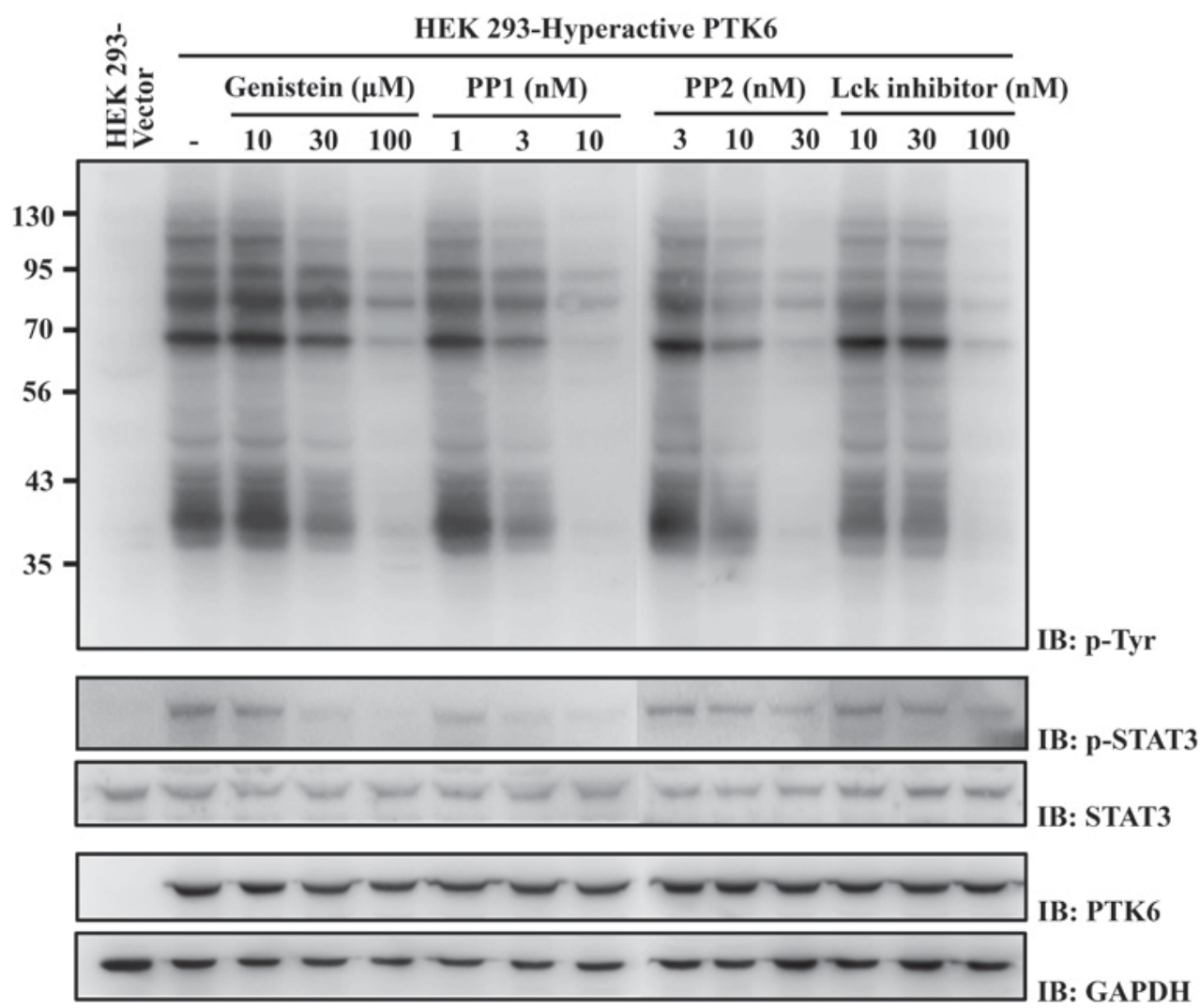

Figure 1. Effects of selected chemicals on the phosphorylation of cellular proteins and a specific PTK6 substrate, STAT3, in HEK 293 cells. HEK 293 cells stably expressing hyperactive PTK6 were incubated with the indicated concentrations of chemicals for $48 \mathrm{~h}$. Cell lysates were analyzed by western blotting using anti-phospho-tyrosine (4G10), anti-phospho-STAT3, anti-STAT3, anti-PTK6 and anti-GAPDH antibodies. The numbers on the left of the top panel indicate apparent molecular weights in kDa. HEK, human embryonic kidney; PP, pyrazolopyrimidine; Lck, lymphocyte-specific protein tyrosine kinase; PTK, protein tyrosine kinase; STAT, signal transducer and activator of transcription; p-, phosphorylated.

This result suggested that PP1, PP2 and the Lck inhibitor were highly selective for PTK6 compared with other PTKs, including the SFK family members, at the cellular level.

PP1, PP2 and Lck inhibitor inhibit the phosphorylation of PTK6 substrate proteins in HEK 293 cells. To analyze whether
PP1, PP2 and the Lck inhibitor block the PTK6-mediated signaling pathway, HEK 293 cells expressing hyperactive PTK6 were treated with these chemicals at concentrations i) lower than, ii) approximately the same as, and iii) higher than their $\mathrm{IC}_{50}$ values. Phosphorylation of STAT3, which is a known specific substrate of PTK6 (22), was inhibited at 
A

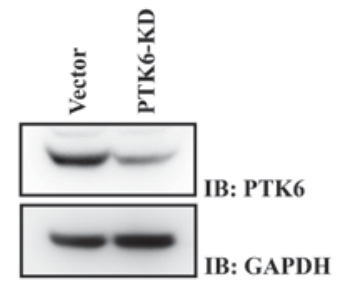

C

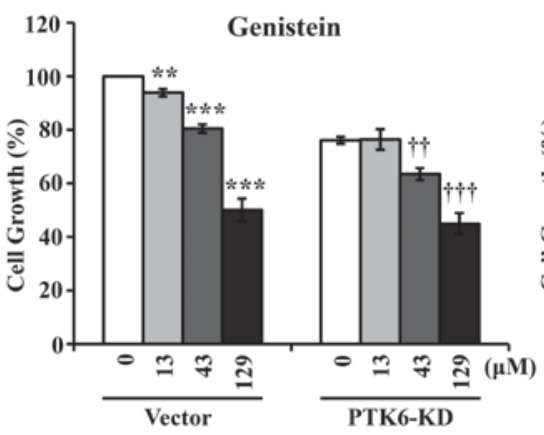

$\mathbf{E}$

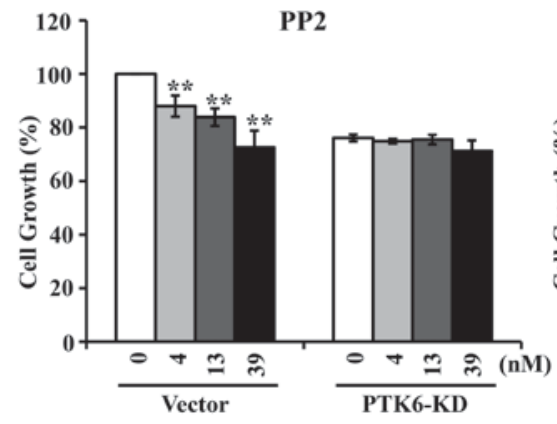

B

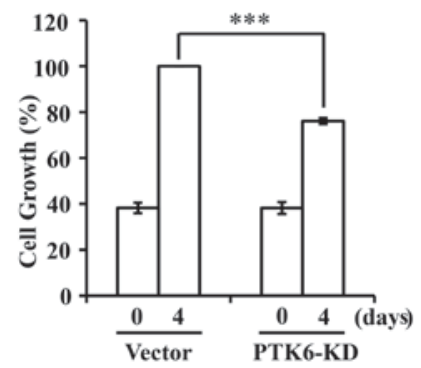

D

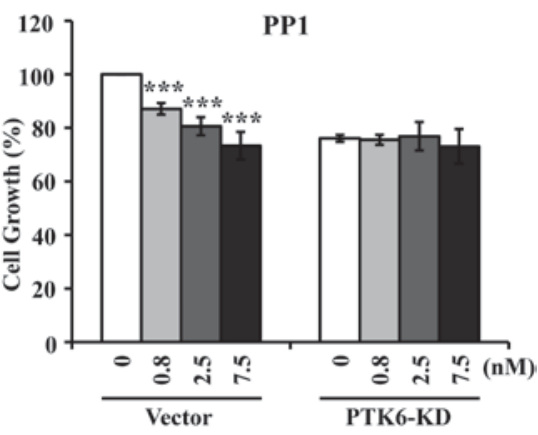

F

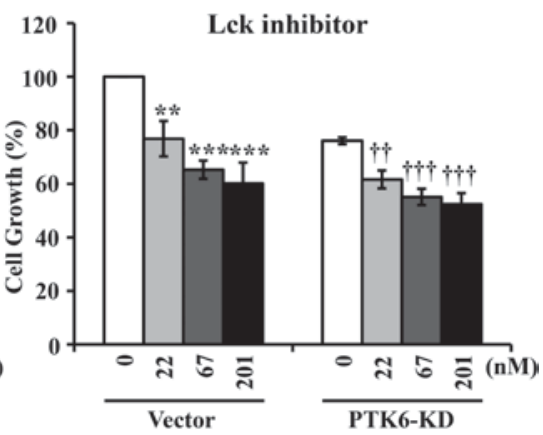

Figure 2. Effects of PTK6 inhibitors on the proliferation of breast cancer T-47D cells. Empty vector-transfected (Vector) and PTK6-knockdown (PTK6-KD) T-47D cells were generated by stable transfection of pLKO.1 and pLKO.1-small hairpin RNA PTK6, respectively (12). (A) Analysis of PTK6 expression levels by western blotting using an anti-PTK6 antibody. (B) Proliferation of Vector and PTK6-KD T-47D cells. (C) Effect of genistein on Vector and PTK6-KD T-47D cells. (D) Effect of PP1 on Vector and PTK6-KD T-47D cells. (E) Effect of PP2 on Vector and PTK6-KD T-47D cells. (F) Effect of a Lck inhibitor on Vector and PTK6-KD T-47D cells. Vector and PTK6-KD cells were incubated in complete medium containing the indicated concentrations of chemicals for 4 days and then subjected to MTT assay. All data are expressed as the mean \pm standard deviation values of three independent experiments, each performed in duplicate. ${ }^{* * *} \mathrm{P}<0.01,{ }^{* * * *} \mathrm{P}<0.001$ vs. Vector T-47D cells without inhibitors. ${ }^{\dagger} \mathrm{P}<0.01,{ }^{\dagger \dagger} \mathrm{P}<0.001$ vs. PTK6-KD T-47D cells without inhibitors. PTK, protein tyrosine kinase; KD, knockdown; PP, pyrazolopyrimidine; Lck, lymphocyte-specific protein tyrosine kinase.

concentrations equal or greater than the $\mathrm{IC}_{50}$ value of each chemical (Fig. 1, mid panel).

PP1 and PP2 inhibit the PTK6-mediated proliferation of $T-47 D$ cells. PTK6 is often expressed in breast cancer cell lines (3). Knockdown of PTK6 decreases the proliferation of breast cancer cells (14). Consistent with this observation, the silencing of PTK6 in breast carcinoma T-47D cells using a small hairpin RNA vector suppressed $\sim 24 \%$ of cell proliferation, compared with vector transfection (Fig. 2A and B). PP1, PP2, the Lck inhibitor and genistein (used as a control) were applied to T-47D cells at concentrations of 0.33-, 1- and 3-fold their $\mathrm{IC}_{50}$ values. PP1 and PP2 inhibited the proliferation of vector-transfected T-47D cells in a dose-dependent manner, but did not affect the proliferation of PTK6-knockdown T-47D cells at values of $\leq 3$-fold their $\mathrm{IC}_{50}$ values (Fig. $2 \mathrm{D}$ and $\mathrm{E}$ ). However, the Lck inhibitor and genistein suppressed the proliferation of both vector-transfected and PTK6-knockdown T-47D cells (Fig. 2C and F). These results suggest that the Lck inhibitor is not specific for PTK6, which is similar to the general PTK inhibitor genistein (23).

\section{Discussion}

In our study, PP1, PP2 and a Lck inhibitor were screened as potential inhibitors for PTK6 using an in vitro kinase assay. These chemicals were initially developed as ATP-competitive inhibitors of SFKs $(21,22)$. PP1 inhibits Lck, Fyn and Src with $\mathrm{IC}_{50}$ values of 5, 6 and $170 \mathrm{nM}$, respectively, as assessed with an in vitro kinase assay (20). PP2 inhibits Lck and Fyn with $\mathrm{IC}_{50}$ values of 5 and $6 \mathrm{nM}$, respectively (20). The Lck inhibitor was developed as a derivative of PP1 and PP2, and inhibits Lck and Src with $\mathrm{IC}_{50}$ values of $<1$ and $70 \mathrm{nM}$, respectively (21). These chemicals were widely used to investigate 
the physiological roles for SFKs, but were not used in human clinical trials. PTK6 is evolutionarily distinct from, but still closely associated with, SFKs (2). Thus, it is expected that PP1, PP2 and the Lck inhibitor inhibit PTK6.

Although PP1 and PP2 are more selective for SFKs than the previous generation of PTK inhibitors (including herbimycin A and genistein), they can inhibit off-target kinases (including C-terminal Src kinase, ephrin type-A receptor 2, platelet-derived growth factor receptor, fibroblast growth factor receptor 1, p21 activated kinase, receptor-interacting

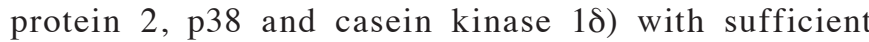
potency (24-27). When the selectivity of these chemicals for various PTKs was analyzed in HEK 293 cells expressing one of the PTKs, they displayed high selectivity for PTK6 over various SFK members, including Src, Fyn, Lck, and other PTK family members such as Bmx and EGFR. In particular, PP1 and PP2 inhibited PTK6 activity at $\mathrm{IC}_{50}$ values of 2.5 and $13.0 \mathrm{nM}$, respectively. Although they also inhibited the catalytic activities of other PTKs, including SFKs, their $\mathrm{IC}_{50}$ values were mostly at micro-molar concentrations. Incubation of T-47D cells with 0.8-7.5 nM PP1 or 4.0-39.0 nM PP2 reduced the PTK6-dependent proliferation of T-47D cells without a decrease in the proliferation of PTK6-knockdown cells. The Lck inhibitor also exhibited inhibitory selectivity for PTK6, but reduced the proliferation of T-47D cells in a PTK6-independent manner. These results demonstrate that PP1 and PP2 reduce the PTK6-mediated signaling pathways and cell proliferation in PTK6-positive cells. Thus, it can be suggested that PP1 and PP2 could be applied as therapeutic agents in PTK6-positive malignant diseases.

Resistance to chemotherapy and molecularly targeted therapies is a major problem confronting current cancer research. The results of a recent study indicated that PTK6 confers resistance of breast cancer SUM102 cells to cetuximab, an EGFR-blocking antibody that is approved for the treatment of several types of human solid tumors (28). Knockdown of PTK6 sensitized the cells to cetuximab by inducing apoptosis. Assuming that PTK6 catalytic activity is essential for drug resistance (28), PTK6 inhibitors such as PP1 and PP2 may be useful for the treatment of chemotherapy-resistant cancer cells.

\section{Acknowledgements}

The present study was supported by a grant from the National Research Foundation of Korea funded by the Ministry of Science, ICT \& Future Planning (grant no. 2014M3C9A2064536).

\section{References}

1. Mitchell PJ, Barker KT, Martindale JE, Kamalati T, Lowe PN, Page MJ, Gusterson BA and Crompton MR: Cloning and characterisation of cDNAs encoding a novel non-receptor tyrosine kinase, brk, expressed in human breast tumours. Oncogene 9: 2383-2390, 1994.

2. Lee H, Kim M, Lee KH, Kang KN and Lee ST: Exon-intron structure of the human PTK6 gene demonstrates that PTK6 constitutes a distinct family of non-receptor tyrosine kinase. Mol Cells 8: 401-407, 1998.

3. Barker KT, Jackson LE and Crompton MR: BRK tyrosine kinase expression in a high proportion of human breast carcinomas Oncogene 15: 799-805, 1997.
4. Brauer PM and Tyner AL: Building a better understanding of the intracellular tyrosine kinase PTK6-BRK by BRK. Biochim Biophys Acta 1806: 66-73, 2010.

5. Mizuguchi Y, Specht S, Isse K, Sasatomi E, Lunz JG III, Takizawa $\mathrm{T}$ and Demetris AJ: Breast tumor kinase/protein tyrosine kinase 6 (Brk/PTK6) activity in normal and neoplastic biliary epithelia. J Hepatol 63: 399-407, 2015.

6. Kamalati T, Jolin HE, Mitchell PJ, Barker KT, Jackson LE, Dean CJ, Page MJ, Gusterson BA and Crompton MR: Brk, a breast tumor-derived non-receptor protein-tyrosine kinase, sensitizes mammary epithelial cells to epidermal growth factor. J Biol Chem 271: 30956-30963, 1996.

7. Chen HY, Shen CH, Tsai YT, Lin FC, Huang YP and Chen RH: Brk activates racl and promotes cell migration and invasion by phosphorylating paxillin. Mol Cell Biol 24: 10558-10572, 2004.

8. Ie Kim H and Lee ST: Oncogenic functions of PTK6 are enhanced by its targeting to plasma membrane but abolished by its targeting to nucleus. J Biochem 146: 133-139, 2009.

9. Peng M, Emmadi R, Wang Z, Wiley EL, Gann PH, Khan SA, Banerji N, McDonald W, Asztalos S, Pham TN, et al: PTK6/BRK is expressed in the normal mammary gland and activated at the plasma membrane in breast tumors. Oncotarget 5: 6038-6048, 2014.

10. Ostrander JH, Daniel AR and Lange CA: Brk/PTK6 signaling in normal and cancer cell models. Curr Opin Pharmacol 10: 662-669, 2010.

11. Goel RK and Lukong KE: Tracing the footprints of the breast cancer oncogene BRK-Past till present. Biochim Biophys Acta 1856: 39-54, 2015.

12. Kang SA, Lee ES, Yoon HY, Randazzo PA and Lee ST: PTK6 inhibits down-regulation of EGF receptor through phosphorylation of ARAP1. J Biol Chem 285: 26013-26021, 2010.

13. Tsui T and Miller WT: Cancer-associated mutations in breast tumor kinase/PTK6 differentially affect enzyme activity and substrate recognition. Biochemistry 54: 3173-3182, 2015.

14. Harvey AJ and Crompton MR: The Brk protein tyrosine kinase as a therapeutic target in cancer: Opportunities and challenges. Anticancer Drugs 15: 107-111, 2004.

15. Shim HJ, Yang HR, Kim HIe, Kang SA, No KT, Jung YH and Lee ST: Discovery of (E)-5-(benzylideneamino)-1H-benzo[d] imidazol-2(3H)-one derivatives as inhibitors for PTK6. Bioorg Med Chem Lett 24: 4659-4663, 2014.

16. Zeng H, Belanger DB, Curran PJ, Shipps GW Jr, Miao H, Bracken JB, Arshad Siddiqui M, Malkowski M and Wang Y: Discovery of novel imidazo[1,2-a]pyrazin-8-amines as Brk/PTK6 inhibitors. Bioorg Med Chem Lett 21: 5870-5875, 2011.

17. Mahmoud KA, Krug M, Wersig T, Slynko I, Schächtele C, Totzke F, Sippl W and Hilgeroth A: Discovery of 4-anilino $\alpha$-carbolines as novel Brk inhibitors. Bioorg Med Chem Lett 24: 1948-1951, 2014.

18. Kim HIe and Lee ST: An intramolecular interaction between $\mathrm{SH} 2-\mathrm{kinase}$ linker and kinase domain is essential for the catalytic activity of protein-tyrosine kinase-6. J Biol Chem 280: 28973-28980, 2005.

19. Kang SA, Cho HS, Yoon JB, Chung IK and Lee ST: Hsp90 rescues PTK6 from proteasomal degradation in breast cancer cells. Biochem J 447: 313-320, 2012.

20. Hanke JH, Gardner JP, Dow RL, Changelian PS, Brissette WH, Weringer EJ, Pollok BA and Connelly PA: Discovery of a novel, potent and Src family-selective tyrosine kinase inhibitor. Study of Lck- and FynT-dependent T cell activation. J Biol Chem 271: 695-701, 1996.

21. Arnold LD, Calderwood DJ, Dixon RW, Johnston ND, Kamens JS, Munschauer R, Rafferty P and Ratnofsky SE: Pyrrolo[2,3-d] pyrimidines containing an extended 5-substituent as potent and selective inhibitors of lck I. Bioorg Med Chem Lett 10: 2167-2170, 2000.

22. Liu L, Gao Y, Qiu H, Miller WT, Poli V and Reich NC: Identification of STAT3 as a specific substrate of breast tumor kinase. Oncogene 25: 4904-4912, 2006

23. Smal C, Cardoen S, Bertrand L, Delacauw A, Ferrant A, Van den Berghe G, Van Den Neste E and Bontemps F: Activation of deoxycytidine kinase by protein kinase inhibitors and okadaic acid in leukemic cells. Biochem Phamacol 68: 95-103, 2004.

24. Summy JM, Trevino JG, Lesslie DP, Baker CH, Shakespeare WC, Wang Y, Sundaramoorthi R, Metcalf CA III, Keats JA, Sawyer TK and Gallick GE: AP23846, a novel and highly potent Src family kinase inhibitor, reduces vascular endothelial growth factor and interleukin-8 expression in human solid tumor cell lines and abrogates downstream angiogenic processes. Mol Cancer Ther 4: 1900-1911, 2005. 
25. Ma QL, Yang F, Frautschy SA and Cole GM: PAK in Alzheimer disease, Huntington disease and X-linked mental retardation. Cell Logist 2: 117-125, 2012.

26. Bain J, McLauchlan H, Elliott M and Cohen P: The specificities of protein kinase inhibitors: An update. Biochem J 371: 199-204, 2003.

27. Bain J, Plater L, Elliott M, Shpiro N, Hastie CJ, McLauchlan H, Klevernic I, Arthur JS, Alessi DR and Cohen P: The selectivity of protein kinase inhibitors: A further update. Biochem J 408: 297-315, 2007.
28. Li X, Lu Y, Liang K, Hsu JM, Albarracin C, Mills GB, Hung MC and Fan Z: Brk/PTK6 sustains activated EGFR signaling through inhibiting EGFR degradation and transactivating EGFR. Oncogene 31: 4372-4383, 2012. 